\title{
Variability of the Atlantic thermohaline circulation described by three-dimensional empirical orthogonal functions
}

Article

Accepted Version

Hawkins, E. and Sutton, R. (2007) Variability of the Atlantic thermohaline circulation described by three-dimensional empirical orthogonal functions. Climate Dynamics, 29 (7-8). pp. 745-762. ISSN 0930-7575 doi:

https://doi.org/10.1007/s00382-007-0263-8 Available at https://centaur.reading.ac.uk/794/

It is advisable to refer to the publisher's version if you intend to cite from the work. See Guidance on citing.

Published version at: http://dx.doi.org/10.1007/s00382-007-0263-8

To link to this article DOI: http://dx.doi.org/10.1007/s00382-007-0263-8

Publisher: Springer

Publisher statement: The original publication is available at www.springerlink.com

All outputs in CentAUR are protected by Intellectual Property Rights law, including copyright law. Copyright and IPR is retained by the creators or other copyright holders. Terms and conditions for use of this material are defined in the End User Agreement.

www.reading.ac.uk/centaur 
Central Archive at the University of Reading

Reading's research outputs online 


\section{Variability of the Atlantic thermohaline circulation described by three-dimensional empirical orthogonal functions}

\section{Ed Hawkins • Rowan Sutton}

Note: This is the author's version of the paper - the published version is available from www.springer.com

Received: 9th November 2006 / Accepted: 12th April 2007

\begin{abstract}
We describe the use of bivariate three-dimensional empirical orthogonal functions (EOFs) in characterising low frequency variability of the Atlantic thermohaline circulation (THC) in the Hadley Centre global climate model, HadCM3. We find that the leading two modes are well correlated with an index of the meridional overturning circulation (MOC) on decadal timescales, with the leading mode alone accounting for $54 \%$ of the decadal variance. Episodes of coherent oscillations in the subspace of the leading EOFs are identified; these episodes are of great interest for the predictability of the THC, and could indicate the existence of different regimes of natural variability. The mechanism identified for the multidecadal variability is an internal ocean mode, dominated by changes in convection in the Nordic Seas, which lead the changes in the MOC by a few years. Variations in salinity transports from the Arctic and from the North Atlantic are the main feedbacks which control the oscillation. This mode has a weak feedback onto the atmosphere and hence a surface climatic influence. Interestingly, some of these climate impacts lead the changes in the overturning. There are also similarities to observed multi-decadal climate variability.
\end{abstract}

\section{E.Hawkins • R. Sutton}

The Walker Institute, Department of Meteorology, University of Reading, Reading. RG6 6BB. UK.

e-mail: e.hawkins@reading.ac.uk

\section{Introduction}

The thermohaline circulation (THC) is a global pattern of currents that arises from gradients in density, and hence hydrostatic pressure, between different regions in the world's oceans. In the Atlantic Ocean the THC is associated with meridional overturning in which a northward flow of light surface waters is balanced by a southward flow of dense deep waters. Since the surface waters are warm while the deep waters are cool, this overturning transports heat northwards, and helps to maintain the climate at high latitudes.

Although the THC is often characterised in terms of a two-dimensional (zonal mean) meridional overturning stream function, in reality it has a complicated threedimensional structure. The important density gradients arise not simply in the meridional direction but also in the zonal direction, as required to maintain approximate geostrophic balance of the meridional flows. Furthermore, localised features such as overflows, and the southward flowing Deep Western Boundary Current (DWBC), are known to play important roles.

The complex spatial (and temporal) structure of the THC is one of the barriers to progress in understanding ocean circulation. In the face of this complexity, it is reasonable to ask whether there may be efficient ways of representing the THC that retain some of the simplicity of a meridional stream function (in particular, many fewer degrees of freedom than the full system) but provide a more accurate representation of the three-dimensional dynamics. Besides their value for conceptual understanding, efficient representations have found many applications in climate science, e.g. for identifying dominant modes of variability, for comparing models with one another and with observations, and for studies of predictability (e.g. Kleeman et al. 2003).

Principal Component Analysis (PCA), also known as Empirical Orthogonal Function (EOF) analysis, is one of the most common tools for the efficient representation of large data sets (Preisendorfer 1988). In climate science PCA is typically used to provide a representation of a space-time data set in terms of a set of mathematically orthogonal spatial functions (the EOFs), each of which is as- 
E. Hawkins \& R. Sutton: Variability of the Atlantic thermohaline circulation

sociated with a time series or 'principal component' (PC). Like the EOFs, the PCs are orthogonal. The decomposition provided by conventional PCA has the property that the first EOF/PC pair, or 'mode', accounts for the largest possible fraction of the total variance in the dataset, while subsequent $\mathrm{EOF} / \mathrm{PC}$ pairs account for maximal variance subject to the constraint of orthogonality to the lower order modes.

In this study we investigate the efficient representation of the Atlantic THC using PCA. Specifically, we use PCA to examine THC variability in a long control integration of a coupled climate model (HadCM3). Because we are interested in the three-dimensional structure of the THC, we use a $3 \mathrm{D}$ state vector.

Several previous studies have analysed various aspects of $\mathrm{THC}$ variability in HadCM3 and have shown variability over a wide range of frequencies. Vellinga and $\mathrm{Wu}$ (2004) presented a mechanism to explain multi-decadal THC variations through slow advection of salinity anomalies from the tropical Atlantic to the North Atlantic. They argued that the salinity anomalies are generated by THCinduced shifts in the location of the ITCZ and that, in the North Atlantic, these anomalies act to reverse the phase of the oscillation by changing the upper ocean density. Dong and Sutton (2005) described an irregular, damped THC oscillation with a period of 25 years in the same model. In this case the mechanism for phase reversal involves changes in the strength of the subpolar gyre, which modulate the transport of saline waters into the Nordic Seas. The subsequent changes in the density of the Nordic Seas alter the THC.

Multi-decadal variability of the THC has also been studied in other coupled climate models. For example, Delworth et al. (1997) described a 40-80 year oscillation of the THC in the GFDL model which was found to be associated with fluctuations in the Arctic, Greenland Sea and in the intensity of the East Greenland Current. Further work (Delworth and Greatbatch 2000) described a mechanism similar to that later found by Dong and Sutton (2005). Delworth and Greatbatch (2000) demonstrated that the timescale was determined by the ocean but that surface flux forcing by the atmosphere was important for exciting the THC variability. Jungclaus et al. (2005) analysed multi-decadal variability of the overturning strength and associated heat transport in the ECHAM5/MPI-OM model. In this model, which has a relatively high resolution at high latitudes, they found that variations in the Atlantic salt and heat transport drive circulation changes in the Nordic Seas. These circulation changes modulate the storage and release of freshwater from the Arctic. Variations in the freshwater export from the Arctic to the convection regions in the Labrador Sea modulate the overturning strength, which in turn alters the Atlantic salt and heat transports.

There is also evidence from observations of multi-decadal variability that may be caused by the THC. In partic- ular, variability of northern hemisphere SSTs (especially in the Atlantic), with periods of $60-100$ years, is found in proxy reconstructions of the climate and in the instrumental record (e.g. Delworth and Mann 2000, Knight et al. 2005). Polyakov et al. (2007) describe observations of strong multi-decadal variability in the Arctic region during the past 100 years and suggest that these changes may regulate the thermohaline circulation. Identifying the causes of this variability will aid future climate projections.

The structure of the paper is as follows. In Section 2 we briefly describe the relevant features of the model used and introduce our indices for characterising the overturning and heat transport. The methodology used to estimate the three-dimensional EOFs is described in Section 3 and the results are presented in Section 4. We conclude and discuss our results in Section 5.

\section{Model description and data}

In the subsequent analysis we use annual mean data from an extended control run (1600 years) of the Hadley Centre climate model (HadCM3, Gordon et al. 2000). The model details are given in Gordon et al. (2000) and references therein, and here we give a brief summary. HadCM3 is a global coupled ocean-atmosphere model with an atmospheric resolution of $2.5^{\circ} \times 3.75^{\circ}$ and 19 vertical levels. The ocean component has a resolution of $1.25^{\circ} \times 1.25^{\circ}$ with 20 vertical levels (shown in Table 1). The outflow from the Mediterranean is not explicitly resolved in the model. Instead it is parameterised by mixing between adjacent grid boxes on either side of the Straits of Gibraltar, in the upper $1200 \mathrm{~m}$, with the parameter chosen to simulate a transport of $1 \mathrm{~Sv}$ from the Mediterranean into the Atlantic (Gordon et al. 2000). The model does not require flux adjustment to maintain a stable climate.

\subsection{The mean state}

The mean state of HadCM3 in the control run is shown for potential temperature (Fig. 1a) and salinity (Fig. 1b). In the upper ocean, the Labrador Sea and Arctic Ocean are relatively cool and fresh, while lower latitudes are warmer and saltier. Transport of warm salty waters into the North Atlantic can be seen on the eastern side of the basin, associated with the North Atlantic drift. It is relevant for the work in this paper that on the western side of the Nordic Seas cool, fresh, Arctic water flows southward over warmer, saltier waters that originate in the Atlantic. Gamiz-Fortis and Sutton (2007) showed that the temperature and salinity contrast between these two water masses is somewhat too large in HadCM3 $\left(\sim 3^{\circ} \mathrm{K}, 1.5 \mathrm{psu}\right)$ as compared to observations $\left(\sim 0.5-1^{\circ} \mathrm{K}, 1.0 \mathrm{psu}\right)$. Also of note are the fresh 'bowl' in the Beaufort Gyre region of l the Arctic, and the salty water protruding into the Barents Sea from the Atlantic. 
Table 1: Depth level details for the HadCM3 ocean model

\begin{tabular}{llll}
$\begin{array}{l}\text { Level } \\
\text { number } k\end{array}$ & $\begin{array}{l}\text { Central depth } \\
\text { of level } / \mathrm{m}\end{array}$ & $\begin{array}{l}\text { Bottom depth } \\
\text { of level } / \mathrm{m}\end{array}$ & $\begin{array}{l}\text { Level thickness } \\
\Delta z_{k} / \mathrm{m}\end{array}$ \\
\hline 1 & 5.0 & 10.0 & 10.0 \\
2 & 15.0 & 20.0 & 10.0 \\
3 & 25.0 & 30.0 & 10.0 \\
4 & 35.1 & 40.2 & 10.2 \\
5 & 47.9 & 55.5 & 15.3 \\
6 & 67.0 & 78.5 & 23.0 \\
7 & 95.8 & 113.0 & 34.5 \\
8 & 138.9 & 164.8 & 51.8 \\
9 & 203.7 & 242.6 & 77.8 \\
10 & 301.0 & 359.4 & 116.8 \\
11 & 447.1 & 534.7 & 175.3 \\
12 & 666.3 & 797.9 & 263.2 \\
13 & 995.6 & 1193.2 & 395.3 \\
14 & 1500.9 & 1808.5 & 615.3 \\
15 & 2116.1 & 2423.8 & 615.3 \\
16 & 2731.4 & 3039.0 & 615.2 \\
17 & 3346.6 & 3654.3 & 615.3 \\
18 & 3961.9 & 4269.5 & 615.2 \\
19 & 4577.1 & 4884.8 & 615.3 \\
20 & 5192.4 & 5500.1 & 615.3 \\
\hline
\end{tabular}

As described by Gordon et al. (2000) for an earlier World Ocean Atlas, the mean SST field in the model reproduces most of the characteristics of the observations in the World Ocean Atlas (Levitus et al. 2006) to within $1^{\circ} \mathrm{C}$ over much of the ocean. The largest discrepancies, of over $3^{\circ} \mathrm{C}$ (and up to $6^{\circ} \mathrm{C}$ ), are in regions of large SST gradients, including the North Atlantic Current (NAC) region where the model is too cool. Just to the north of Iceland the model is too warm by $\sim 3^{\circ} \mathrm{C}$. The mean SSS field is well modelled to within 1 psu in most regions (Pardaens et al. 2003). The model is too salty in the Gulf Stream region $(\sim 2 \mathrm{psu})$ and along the Northern Russian coast (up to $8 \mathrm{psu}$ ), and too fresh in the Beaufort Gyre region of the Arctic Ocean $(\sim 2 \mathrm{psu})$. Below the surface in the Atlantic the model is generally too warm $\left(\sim 2^{\circ} \mathrm{C}\right)$ and too salty $(\sim 0.5 \mathrm{psu})$.

\subsection{Definition of climate indices}

We define an MOC index (MOI) from the control run as the detrended annual mean streamfunction at a depth of $996 \mathrm{~m}$ in the latitude band $27.5^{\circ}-32.5^{\circ} \mathrm{N}$, which is where the ocean heat transport reaches a maximum. This definition of a MOI was used by Dong and Sutton (2005) and has a mean value of $16.3 \mathrm{~Sv}$. The standard deviation of this index is $1.0 \mathrm{~Sv}$. A wavelet analysis of the overturning strength for HadCM3 is shown in Figure 4 of Vellinga and $\mathrm{Wu}(2004)$ and shows there is significant power on decadal and centennial timescales.

We also define an ocean heat transport (OHT) index as the total northward heat transport averaged over the north Atlantic $\left(0-70^{\circ} \mathrm{N}\right)$. The MOI and $\mathrm{OHT}$ index have a correlation of 0.77 and are in phase. This correlation increases to 0.93 for decadally filtered indices. It is found that the MOI defined here has a higher correlation with the OHT than an MOC index based on the maximum value of the streamfunction over the Atlantic basin (as used by some other authors), which has a correlation of 0.60 with the OHT. This correlation is relevant as it is the heat transport rather than the strength of the overturning which is more closely related to the ocean's influence on mid-to-high latitude climate.

\section{Calculation of Three-dimens- ional EOFs for the THC}

Empirical Orthogonal Functions (EOFs) are a commonly used tool in atmospheric and oceanic science when attempting to reduce the dimensionality of observations or model data.

The data anomalies (usually as a function of time) are represented by a matrix $D$. Mathematically, the EOFs are the eigenvectors of the covariance (or correlation) matrix of $D$, i.e. the eigenvectors of $D^{\mathrm{T}} D$ (or $D^{\mathrm{T}} D / \sigma_{m} \sigma_{n}$, where $\sigma$ denotes the standard deviation of the anomalies). In practice, these eigenvectors are calculated using a singular value decomposition (SVD) of $D$ rather than calculating the (usually) large matrix $D^{\mathrm{T}} D$.

Most commonly, fields with two space dimensions (latitude, longitude) are considered, but bivariate vertical EOFs have also been examined (e.g. Gavart and De Mey 1997). Here we consider how this methodology can be extended to include an extra spatial dimension in the ocean, i.e. including latitude, longitude and depth simultaneously. The calculation of three-dimensional EOFs is a simple extension of the two-dimensional case. The state vector includes the data anomalies from each depth level at every latitude and longitude grid point. In addition, our state vector includes both potential temperature and salinity. The resulting EOF represents a pattern where the covariance or correlation is maximised jointly in the domain and between variables.

\section{$3.1 \quad$ Weighting EOFs}

In an EOF calculation for atmospheric or oceanic variables it is usual to ensure that each unit surface area is treated equally with respect to its contribution to the total variance. On a regular latitude-longitude grid the areas of each grid box are not equal, but proportional to the cosine of the latitude, so a weighting must be applied to downweight those regions with smaller grid box areas. For the three-dimensional case we also have to consider that the thicknesses of the model depth levels are not uniform (see Table 1). To ensure that each volume of water is treated equally, the depth level thicknesses, as well as the latitude 
(a)
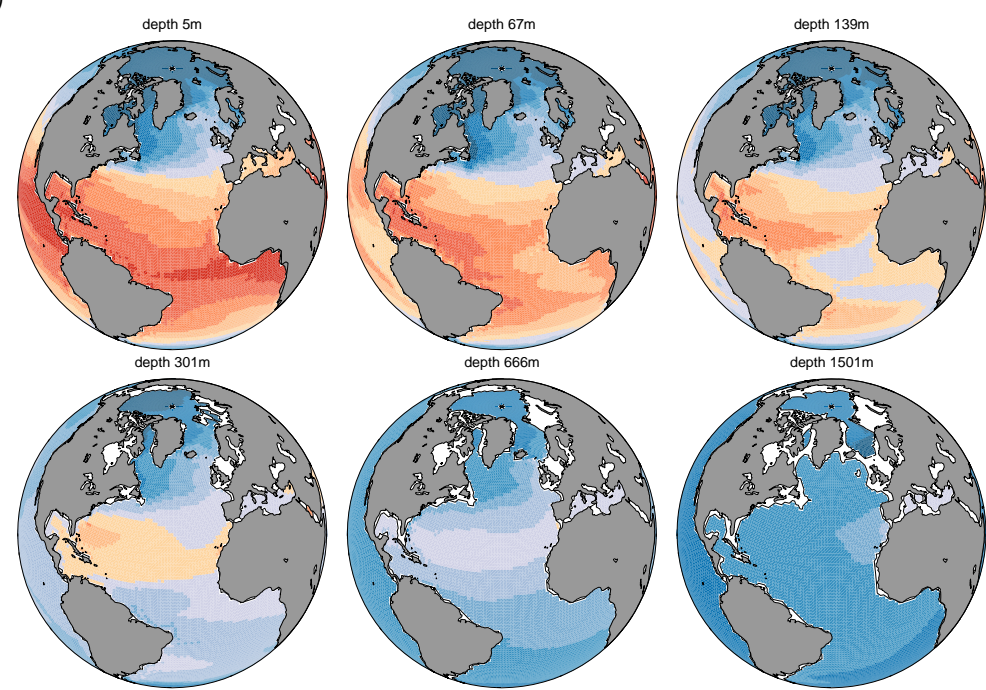

(b)

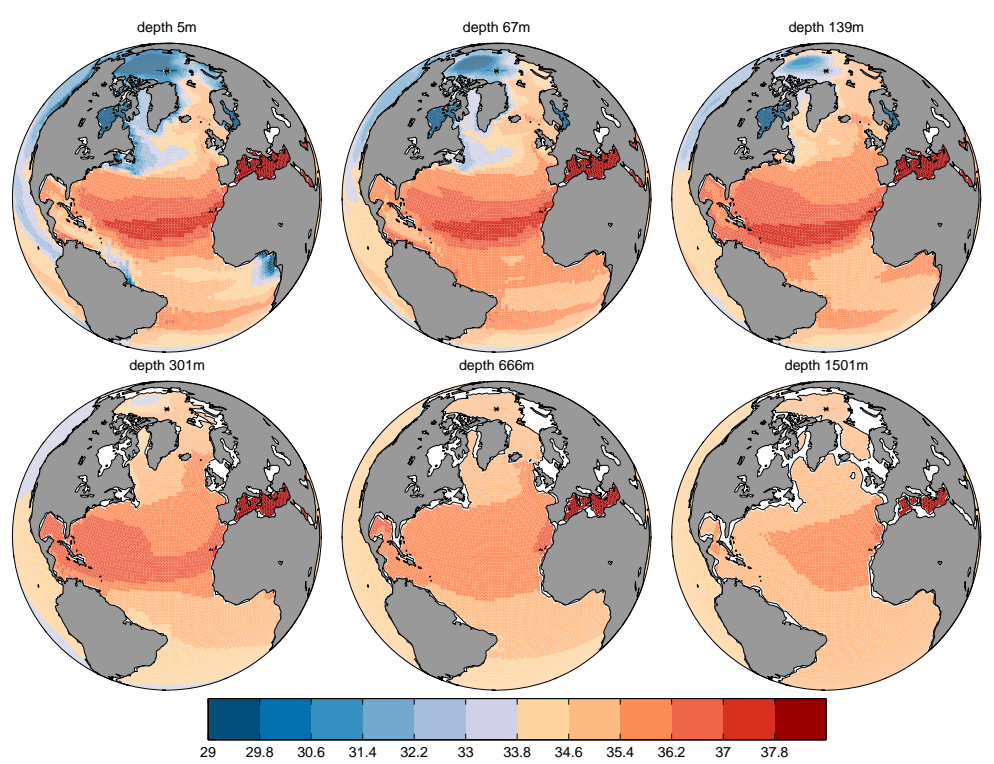

Figure 1: (a) Mean potential temperature $\left({ }^{\circ} \mathrm{C}\right)$, and (b) mean salinity (psu) in the control run of HadCM3 on six depth levels as labelled. The model bathymetry is plotted as a thin black contour.

effect just described, need to be considered. Furthermore, when considering the multivariate case it is also necessary to consider the relative weighting of the different variables.

To ensure that each volume of water is treated equally, the anomalies are weighted by,

$$
w_{i j k}=\sqrt{\Delta z_{k} \cos \left(\phi_{j}\right)}
$$

where $i, j, k$ denote the longitude, latitude and depth directions respectively, $\phi$ is the latitude, and $\Delta z$ is the depth level thickness.

In this particular case we are using salinity anomalies, $S^{\prime}$, and potential temperature anomalies, $\theta^{\prime}$, and are interested in the behaviour of the Atlantic THC. As density anomalies drive the variation of the THC we will use a weighting scheme which depends on the relative contribution to local density for each grid point, hence

$$
\begin{gathered}
v_{i j k}^{\theta^{\prime}}=\operatorname{sgn}\left(\frac{\alpha_{i j k}}{\beta_{i j k}}\right) \sqrt{\left|\frac{\alpha_{i j k}}{\beta_{i j k}}\right|}, \\
v_{i j k}^{S^{\prime}}=1,
\end{gathered}
$$

where $\alpha$ is the thermal expansion coefficient and $\beta$ is the haline contraction coefficient, calculated at each grid point by using the time mean values of $S$ and $\theta$. The square roots in Eqns. 1 and 2 are required as we are estimating the eigenvectors of the product $D^{\mathrm{T}} D$; the covariance (or correlation) matrix will thus have the latitude, level thickness and density contribution weighting required. The sgn 
term in Eqn. 2 is required as $\alpha$ can be negative, so we take the modulus of $\alpha / \beta$ inside the square root.

The total weight for each grid point is then the product of $w_{i j k}$ and the appropriate $v_{i j k}$. The weighting is applied to $D$ prior to carrying out the singular value decomposition from which the EOFs are obtained. The EOFs are then deweighted by the same factor before analysis to ensure the data has real physical units.

\subsection{Normalisation of EOFs}

When using more than one variable, as in this example, it is necessary to remove the effect of the arbitrary choice of units. In the covariance case this is achieved by normalising each field by the spatial average of the temporal standard deviation of the field.

We first computed covariance EOFs and found that they were dominated by variability in the upper ocean, and the leading PCs were not well correlated with the MOI. To highlight more deeply reaching basin-scale dynamics we therefore tried correlation EOFs. In a correlation EOF analysis, the state vector is normalised so that the anomalies at each grid point have unit standard deviation in time. This approach vastly improved the correlation between the PCs and the MOI and so is adopted here.

\subsection{Robustness of EOFs}

The data considered are annual mean fields of potential temperature and salinity which have been detrended using a second order polynomial over the time period analysed. We do not use the first 500 years of the control run to minimise the effects of spin-up in the deep ocean, and find that using a second order polynomial to detrend the data gives a significantly better correlation between the resulting principal components and the MOI. We use the remaining 1100 years (nominally the years 2350 - 3449) of the control run to include as many multi-decadal cycles as possible.

Our chosen domain is $20^{\circ} \mathrm{S}-90^{\circ} \mathrm{N}$ and $100^{\circ} \mathrm{W}-20^{\circ} \mathrm{E}$ to include most of the Atlantic (the small part of the Pacific in this region is masked out). We chose to use twelve depth levels down to $1501 \mathrm{~m}$ depth $(1809 \mathrm{~m}$ for the bottom of the level, see Table 1) in the EOF calculation so that most of the primary overturning cell is included (see, e.g. Fig 1a of Vellinga and $\mathrm{Wu} 2004)$. The two levels not included in the calculation are levels $2(15 \mathrm{~m})$ and $4(35 \mathrm{~m})$ and this is done due to computational constraints. The strong coherency between levels near the surface (levels 1 and 3 in the leading EOF have a spatial correlation of 0.98) means that the results are insensitive to this omission.

It is important to ensure that the estimated EOFs are robust, and not an artifact of choices made for time period used, region chosen, depth level selection, detrending or weighting schemes. We therefore performed many tests including changing the lowest depth level included, the number of depth levels, the time period in the control run, the order of the polynomial used for detrending and tried different weighting schemes. Although the detailed results differ between these tests, all give a reasonably consistent pattern for the leading EOF, and so we can be confident about the robustness of this EOF. There is slightly more variation in the second EOF (not shown), but these differences are not enough to affect our later conclusions. There is significant variation in the higher EOFs, which is not surprising as different weighting schemes, for example, can easily give rise to rotations within the sub-space spanned by the leading eigenvectors. Consequently, we will only consider the leading two EOFs further.

Finally, if the calculation is repeated using density and spiciness (Flament 2002) as the variables in the EOF calculation (instead of temperature and salinity) the resulting PCs are also remarkably similar. This finding gives us more confidence that the method is representing the underlying dynamics well.

\section{Results}

\subsection{Bivariate three-dimensional EOFs}

We present a bivariate correlation EOF analysis for 1100 years of potential temperature and salinity data on twelve depth levels to $1501 \mathrm{~m}$ depth. The calculated principal component time series have been normalised to have unit standard deviation, and the respective EOFs are scaled to maintain total variance.

\subsubsection{Eigenspectrum}

Fig. 2 shows the eigenspectrum (blue line) and accumulated fraction of variance explained (green line) for the first ten EOFs. The leading EOF accounts for around $15 \%$ of the total variance, and the first ten EOFs together account for just over $50 \%$. Given the size of the state matrix $(1100 \times 105150$ elements $)$, it is not surprising that the percentages of total variance explained are not large.

The red line in Fig. 2 shows the cumulative fraction of variance of the decadally filtered MOI explained, at zero lag, by the first ten EOFs, and shows that only the first two PCs have a high correlation with the MOI at zero lag. In fact, these are the only PCs to have significant (>99\%) correlation with the filtered MOI at any lag up to \pm 50 years using a t-test (not shown). Note that at zero lag PC2 explains most variance of the MOI. However, as we now discuss, if we vary the lag then the picture changes. 


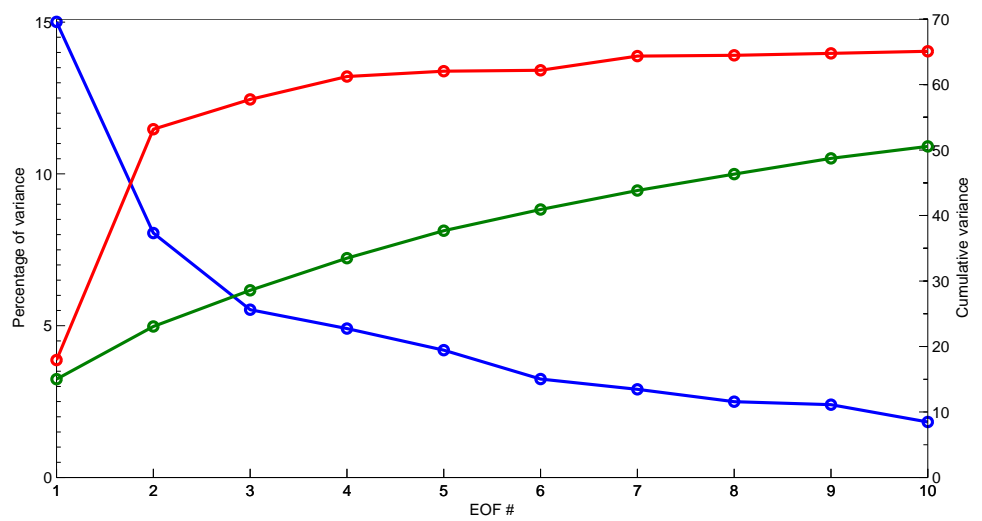

Figure 2: Blue line and left hand axis scale: the eigenspectrum for the 10 leading EOFs. Green line and right hand axis scale: Cumulative fraction of variance explained. Red line and right hand axis scale: Cumulative fraction of variance of the decadally filtered MOI explained, at zero lag.

\subsubsection{Principal components}

The two leading principal components (PCs) are shown in Fig. 3a. There is multi-decadal ${ }^{1}$ variability in each $\mathrm{PC}$, though $\mathrm{PC} 2$ has more high frequency (decadal) oscillations than $\mathrm{PC} 1$. The EOF analysis has naturally selected the lowest frequency modes, since these explain the most variance.

Fig. 3b shows $\mathrm{PC} 1$ and the decadally filtered MOI and OHT index. PC1 has been shifted to maximise the correlation (0.74) with the MOI, with the MOI leading the unfiltered PC1 by 20 years. Allowing for the lag, this leading principal component thus explains $54 \%$ of the variance of the MOI on decadal timescales. This correlation increases to $0.86(74 \%)$ if considering a 30 year filtered MOI. The correlations are similar if using the OHT index rather than the MOI.

For $\mathrm{PC} 2$, we find the largest (absolute) correlation on decadal timescales of -0.61 when $\mathrm{PC} 2$ lags the MOI by 1 year (not shown). The relationship between the two leading PCs is considered further in Section 4.1.4.

The higher modes $(3-10)$ are mostly dominated by surface and very deep ocean signals (not shown). One of the strengths of our EOF approach is that no prior information about the form of the MOC has been used, yet a high correlation is found with the MOI.

\subsubsection{EOF patterns}

The structure of the leading EOF is shown in Fig. $4 .^{2}$ It illustrates the temperature and salinity features present approximately 20 years after an MOI maximum, per unit change in PC1. The features are extremely coherent over many of the depth levels, especially near the surface and so

\footnotetext{
${ }^{1}$ Note that the phrase 'multi-decadal' also includes centennial variability.

${ }^{2}$ The structure of the second EOF is not shown here, but can be seen later in the fourth row $\left(\psi=\frac{3 \pi}{2}\right)$ of Figs. 7,8 , with reversed sign.
}

we show only a representative subset of six levels. In fact, there is a negligible difference in the patterns obtained if we only use these six layers in the EOF calculation itself.

The figures show that in this phase most of the subpolar gyre is anomalously warm and salty near the surface with a peak in the North Atlantic Current (NAC) region of around $0.3 \mathrm{~K}$ and $0.1 \mathrm{psu}$, suggesting increased advection from the Gulf Stream region or a northward displacement of the NAC front. In the west at low latitudes there are cool, fresh anomalies which peak at around $666 \mathrm{~m}(0.3 \mathrm{~K}$ and $0.05 \mathrm{psu})$. In many regions the temperature and salinity anomalies are density compensating, but an exception is found in the Labrador Sea at around $300 \mathrm{~m}$ where the anomalies are both cool and salty, indicating high density. Positive density anomalies are also found in the Nordic Seas (where salinity variations dominate over variations in temperature, not shown). Thus at this phase there is an enhanced meridional density gradient between the high latitude North Atlantic and lower latitudes, consistent with the relatively strong state of the MOC (Thorpe et al. 2001).

The section of the Arctic included in the analysis shows an intriguing fresh (and hence low density) anomaly (up to $0.25 \mathrm{psu}$ ) extending from the surface to a depth of $300 \mathrm{~m}$. This anomaly suggests that variability in the Arctic may respond to, or be part of, the processes which govern the multi-decadal variability of the MOC. Jungclaus et al. (2005) argued that the Arctic Ocean plays an important role in MOC variability in the ECHAM5/MPIOM model, but this possibility has not previously been recognised in HadCM3. (Wu et al. (2004) suggest that the recent observed freshening trend in the North Atlantic originates in the Arctic Ocean in HadCM3, but this is due to anthropogenic effects rather than the natural variability discussed here.) Polyakov et al. (2007) showed that observations of the Arctic climate system over the past century have considerable variability on multi-decadal timescales. 


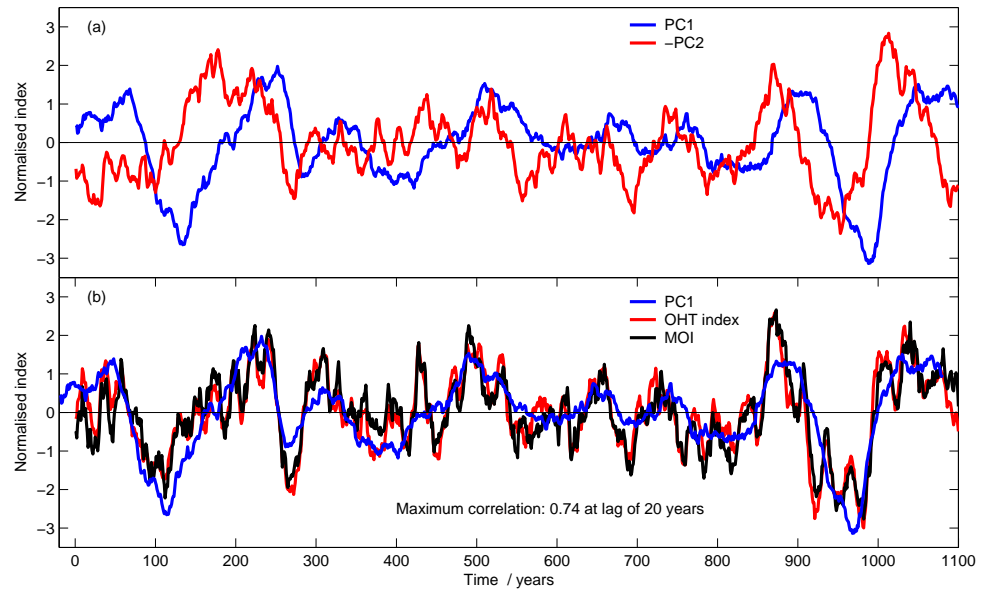

Figure 3: (a) The two leading principal components (PCs) as labelled. Note: The negative of PC2 is plotted to show the correlation with the MOI more clearly. (b) Black line: the meridional overturning circulation index (MOI). Blue line: the leading principal component (PC1) shifted by 20 years to maximise correlation with the MOI - the PC lags the MOI. Red line: the ocean heat transport (OHT) index. The MOI and OHT index have been decadally filtered.

\subsubsection{PC1 - PC2 sub-space analysis}

To examine further the relationship between the leading $\mathrm{PCs}$ it is useful to examine phase space diagrams for pairs of PCs. Fig. 5 shows this analysis for the PC1-PC2 subspace, where the PCs have been decadally filtered. The blue line represents a 214-year period (years 64 - 277) where there is a clear circular feature indicating that these $\mathrm{PCs}$ are oscillating in quadrature for this time period. The red line shows a 216-year period (years 875 - 1090) which shows another, larger, circular feature. The other time periods are more noisy and are shown as grey lines and show no immediate sign of this coherent oscillation. Both of the coherent oscillations last for about $1 \frac{1}{4}$ cycles but start in different regions of the sub-space. It is also interesting to note that they occur at times when the $\mathrm{PC}$ variability has largest amplitude. The black line in Fig. 5 indicates the axis of the MOI extrema, which is found by plotting the MOI against the phase of the oscillation in this sub-space (not shown). These results might indicate the presence of different regimes of variability, ${ }^{3}$ and are of great interest for predictability. Fig. 5 suggests, for example, that the evolution of the MOC may more predictable when starting from an extreme minimum in the $\mathrm{MOC}$ or a large negative value of $\mathrm{PC} 1$, than it is for initial conditions located in other regions of the sub-space. Collins and Sinha (2003) also suggested that there might be enhanced predictability at certain phases of MOC variation in HadCM3. No similar features are seen in sub-spaces involving the higher PCs.

To understand whether this coherent oscillation is a consistent feature of the variability, we analyse the sub-

\footnotetext{
${ }^{3}$ For example, the figure could be evidence of a Hopf bifurcation; the system transitions from a regime with a single equilibrium state to a regime with a limit cycle, excited by stochastic fluctuations (Dijkstra, personal communication).
}

space tendencies. Fig. 6 shows the same evolution (grey line) in the sub-space as in Fig. 5, and the arrows show the mean sub-space tendencies, $\overline{T_{n}}$, averaged over regions of the sub-space, where

$$
T_{n}(t)=\mathrm{PC} n(t+1)-\mathrm{PC} n(t)
$$

for $n=1,2$, and $t$ is the year. The mean vectors $\left(\left[\overline{T_{1}}, \overline{T_{2}}\right]\right)$ are plotted at the mean location in each particular region of the sub-space. The labelled contours indicate the number of points included in the meaning. The arrows show a very coherent circular oscillation in the outer regions of the sub-space as expected from Fig. 5. Surprisingly, the vectors are also coherent in the low amplitude, and more noisy region near the centre of the sub-space. This finding suggests that it may just be the amplitude of this circular oscillation which changes over time. The time taken for one complete orbit is roughly constant ( $\sim 150$ years $)$ with amplitude, i.e. it resembles solid body rotation. Finer scale versions of the figure show similar consistency but are more noisy (not shown).

We do not have enough complete cycles to distinguish whether the amplitude of the oscillation can take any value, or whether there are indeed different amplitude regimes. In either case the circular, low-frequency, oscillation seems to a fundamental feature of the variability and merits further analysis.

\subsection{A mechanism for low frequency vari- ability}

We now analyse the evolution in the PC1-PC2 sub-space to identify the physical processes responsible for the coherent oscillations identified above. 
(a)

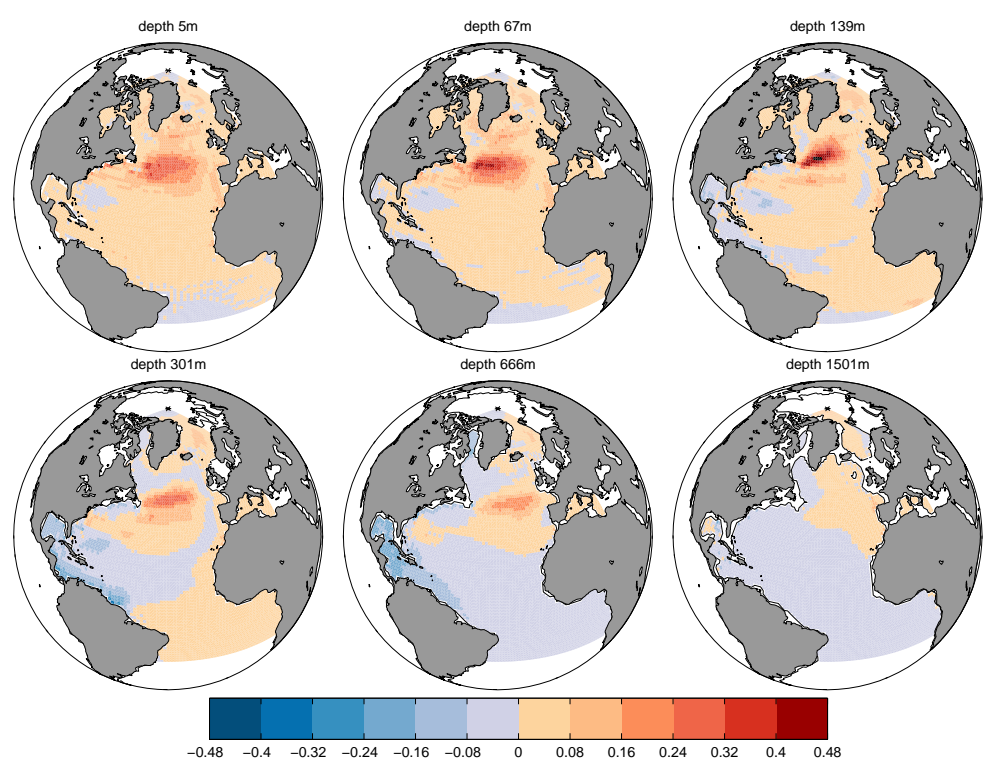

(b)

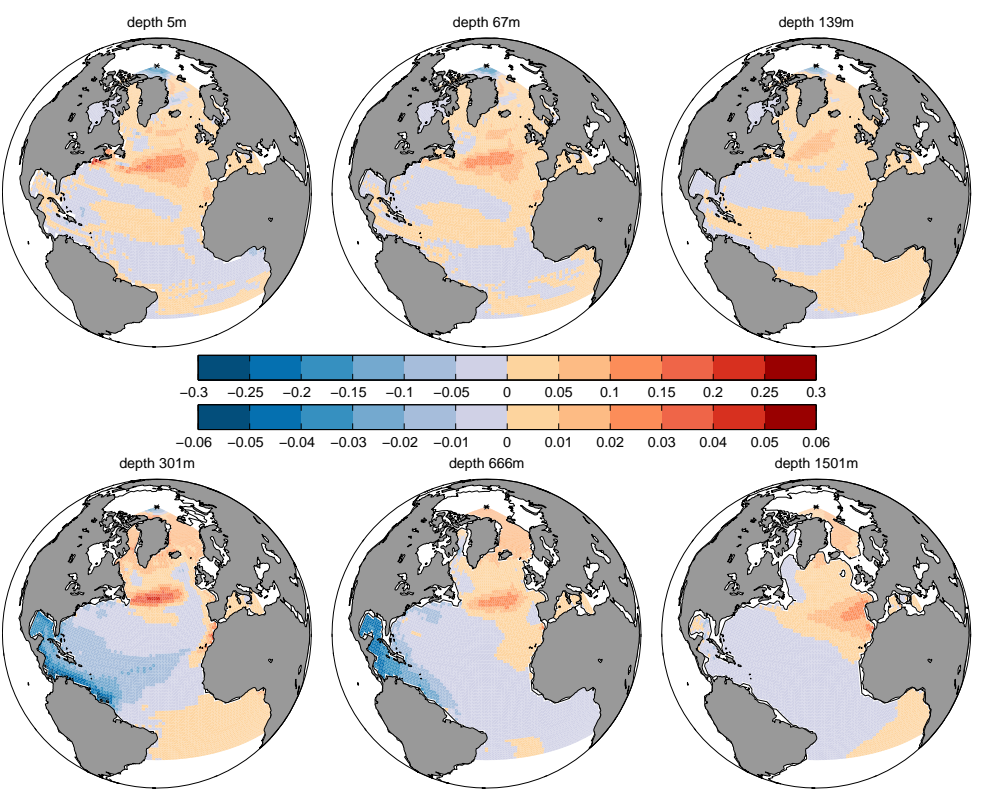

Figure 4: The leading EOF pattern on six depth levels as labelled. The model bathymetry is shown with a thin black contour. (a) Potential temperature in K per unit change of PC1. (b) Salinity in psu per unit change of PC1. Note: salinity colour scale changes to smaller values for the bottom three levels.

\subsubsection{Evolution of anomalies}

As these coherent oscillations are associated with multidecadal MOI variability, the higher frequency variability can be effectively removed by assuming an simplified trajectory in the sub-space. We therefore assume a circular trajectory in the PC1-PC2 sub-space and combine the respective EOF fields for a particular phase, $\psi$, using

$$
\mathrm{EOF}_{\psi}=\cos (\psi) \times \mathrm{EOF} 1+\sin (\psi) \times \mathrm{EOF} 2 .
$$

where $\psi$ is defined relative to $[\mathrm{PC} 1, \mathrm{PC} 2]=[1.0,0.0]$. The evolution of anomalies in the PC1-PC2 sub-space is shown for temperature (Fig. 7) and salinity (Fig. 8), at a selection of depths. ${ }^{4}$ The phases shown are $\psi=\left[\frac{3 \pi}{4}, \pi, \frac{5 \pi}{4}, \frac{3 \pi}{2}, \frac{7 \pi}{4}\right]$, and thus cover $180^{\circ}$ of the oscillation. The initial phase is roughly at a minimum of the $\mathrm{MOC}$, and the evolution through to an MOC maximum is shown. Note that although we will refer to these phases as the 'MOC' they are derived from the simplified circular trajectory. The reverse phases can be obtained by simply changing the sign of the anomalies. Note also that the length of time elapsed between panels is not necessarily constant. The anomalies in the Arctic outside the sector $100^{\circ} \mathrm{W}-20^{\circ} \mathrm{E}$ are not included in the EOF calculation but can be calculated by regress-

\footnotetext{
${ }^{4}$ Fig. 16 is an animated version of these figures.
} 


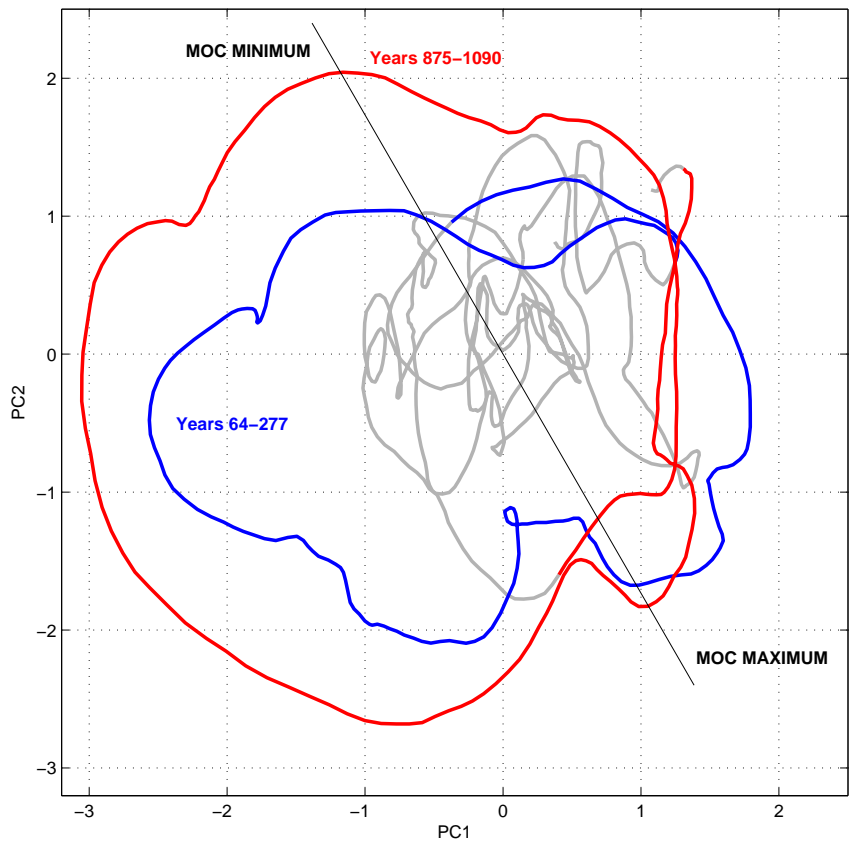

Figure 5: Phase space diagram showing the sub-space spanned by the two leading PCs. The colours, as labelled, denote two particular time periods within the 1100 years analysed, and highlights the time periods where circular oscillations are present. A grey line is used for all other time periods. The PCs have been decadally filtered.

ing the salinity and temperature in this region onto the leading PCs. These regression coefficients are included in the plots for completeness.

These figures show that at an MOC minimum (top row) the largest anomalies in the upper ocean are found in the NAC region (cool and fresh), the Arctic (salty) and in the Nordic seas where it is fresh and mostly cool. At $300 \mathrm{~m}$ and below there are also prominent warm, salty anomalies extending from the Gulf of Mexico along the coast to South America. At $1500 \mathrm{~m}$ and (less clearly) at $666 \mathrm{~m}$ these anomalies appear to extend continuously along the western boundary of the North Atlantic, reaching up to the Labrador Sea. It is likely that the western boundary anomalies are related to the propagation of Kelvin-type waves, which are excited by changes in deep water formation in the North Atlantic. In particular, a reduction in deep water formation, associated with a minimum in the $\mathrm{MOC}$, is expected to lead to a deepening of isopycnals, isotherms and isohalines (Johnson and Marshall 2002). In regions such as along the coast of South America where temperature and salinity decrease with depth (see Fig. 1), this deepening will cause increases in temperature and salinity at a fixed depth, as is seen in the Figs. 7 and 8. The effects of similar deepening can be seen in North Atlantic water hosing experiments, e.g. see Fig 7 of Ottera et al. (2004).

At and below $666 \mathrm{~m}$ the western boundary anomalies

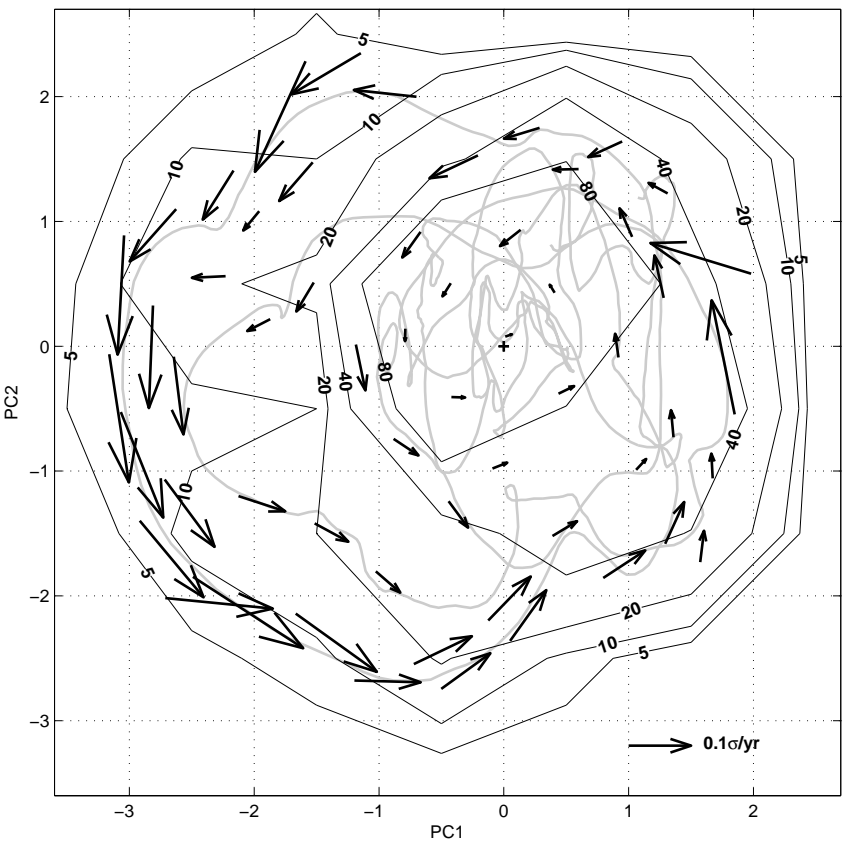

Figure 6: The mean sub-space tendencies (arrows) of the two leading PCs, averaged over square regions of sub-space with unit height and width. There are two sets of arrows, for regions offset by half unit distance in the PC1 direction, thus only half of the arrows are independent. The vector tendencies are centred on the mean position in each region of sub-space. The contours indicate the number of points included in the average in each region of sub-space. The grey line is the phase space trajectory as shown in Fig. 5. The cross is at $[\mathrm{PC} 1, \mathrm{PC} 2]=[0,0]$.

contrast with anomalies of opposite sign on the eastern side of the basin; these eastern anomalies stretch from mid-latitudes up into the Arctic. At $1500 \mathrm{~m}$ there is a large low salinity anomaly that reaches west from Iberia. It is unclear whether this feature is related to anomalous salinity transport from the Mediterranean Sea. Also at $1500 \mathrm{~m}$, on the southern side of the Denmark Strait there is a small tongue of cool, fresh, water, which may be evidence of anomalies in the overflow from the Nordic Seas.

As the oscillation evolves from MOC minimum to MOC maximum the large scale pattern of anomalies is gradually reversed. In many regions, e.g. the NAC, the evolution resembles a standing oscillation, but there are also some propagating features, e.g. at $666 \mathrm{~m}$ the gradual extension of positive salinity and temperature anomalies from the northeast Atlantic into the Arctic (also see the animated anomalies in Fig. 16). Polyakov et al. (2005) observed the propagation of temperature anomalies into the Arctic over several years in a similar manner.

The swings in temperature and salinity are associated with swings in density. Vellinga and $\mathrm{Wu}$ (2004), following Thorpe et al. (2001), showed that in HadCM3 the evolution of the density field, vertically integrated from the 
E. Hawkins \& R. Sutton: Variability of the Atlantic thermohaline circulation

surface to $800 \mathrm{~m}$ is closely related to the evolution of the MOC. (Note that in HadCM3, $800 \mathrm{~m}$ corresponds to the maximum depth of the Denmark Strait). Fig. 9 shows this integral; we see that the MOC minimum is associated with negative density anomalies in the subpolar gyre, with the largest anomalies found near the coast of Greenland in the Labrador Sea, Irminger Sea and on the western side of the Nordic Seas. Positive anomalies are found further south, particularly in the region of the subtropical gyre. Thus there is a negative anomaly in the meridional density gradient. The lower panels show that this gradient gradually reverses sign as the MOC anomaly reverses. Interestingly, the figure also shows large density anomalies in the Arctic Ocean, which peak at a similar time to the minima or maxima in the MOC, and are out of phase with the variations in the subpolar gyre. These Arctic variations were not discussed by Vellinga and $\mathrm{Wu}$ (2004).

Fig. 9 implies that the key question of what mechanism controls the variations of the $\mathrm{MOC}$ can be reduced to the narrower question of what controls the density at high latitudes on multi-decadal timescales. An answer to this question was provided by Vellinga and Wu (2004). However, as we will discuss shortly, our analyses suggest a mechanism which features some important differences from their proposal.

To understand the variations in vertically integrated density we now focus in detail on the western Nordic Seas; our analyses have shown that density variations in this region are a precursor of changes in the MOC. Fig. 10 shows the evolution of vertically integrated density anomalies on the western side of the Nordic Seas at a latitude of $72.5^{\circ}$ $\mathrm{N}$, over a full cycle of the MOC variation. Also shown are the separate contributions to the variations in density that come from variations in temperature and variations in salinity. The figure reveals a number of interesting features. First, the variations in density in this region lead the MOC by $\pi / 4$. Secondly, the variations in density are influenced both by variations in temperature and by variations in salinity, with salinity consistently making the largest contribution. Thirdly, the contributions from temperature and salinity are not in phase. Perhaps surprisingly, in view of their smaller quantitative contribution to density, the variations in temperature are in phase with the variations in density, while the variations in salinity lag by $\pi / 4$. (Hence the salinity in this region is in phase with the MOC).

That variations in density in the western Nordic Seas lead variations in the MOC suggests that this region plays an important role in driving the MOC variability. Such a scenario is plausible in view of the potential for density anomalies in this region to influence the overflows from the Nordic Seas, to modulate deep water formation, and to excite boundary disturbances that can propagate around the basin. Fig. 10, however, indicates that the processes controlling density in this region are quite complex, involving a subtle interplay of temperature and salinity variations.
Our next task, therefore, is to understand these variations.

\subsubsection{The role of convection in the Nordic Seas}

As noted in the discussion of Fig. 1, in the western Nordic Seas, cool, fresh, Arctic water flows southward over warmer, saltier, waters of Atlantic origin. Fig. 11 shows profiles of temperature and salinity for this region, again at $72.5^{\circ} \mathrm{N}$. Panels a and $\mathrm{c}$ show the time mean profiles. The cool, fresh surface waters are clearly seen, and the subsurface temperature maximum, peaking at a depth of $\sim 300 \mathrm{~m}$, is another prominent feature. An important consequence of this subsurface maximum is that vertical mixing associated with convection can raise surface temperature (Gamiz-Fortis and Sutton 2007).

Fig. 11b,d show the evolution of anomalous temperature and salinity profiles from MOC minimum to MOC maximum. An obvious feature of the temperature profiles is the anti-phase variations between the near surface waters and the subsurface waters between $200-1000 \mathrm{~m}$. This vertical structure is precisely what one would expect as a result of variations in vertical mixing, given the mean profile in shown in panel a. At an MOC minimum the near surface waters are anomalously cool and the subsurface is anomalously warm. As the cycle evolves, surface warming and subsurface cooling suggests a progressive increase in vertical mixing until shortly before the MOC maximum. The phase $\left(\psi=\frac{3 \pi}{2}\right)$ when the temperature stratification is at a minimum is also the phase when sea surface temperatures are at a maximum (not just at $72.5^{\circ} \mathrm{N}$, but over most of the Nordic Seas, see Fig. 7). However, the contribution of temperature anomalies to the vertically integrated density (Fig. 10) is at a maximum because it is dominated by the subsurface cooling rather than the near surface warming.

In the absence of any transport effects or surface flux anomalies, we would not expect changes in convection alone to alter the vertically integrated density. However, this statement is only valid if one integrates down to the bottom of the layer in which mixing occurs. When computing Fig. 10 we only integrated down to $800 \mathrm{~m}$ because this depth corresponds to the bottom of the Denmark Strait in HadCM3, and deeper water masses are unlikely to directly affect the transports through the Strait. Fig. 11b, however, suggests that there is significant mixing to greater depths. If the integral is extended in depth we find that the contribution from temperature changes to the changes in vertically averaged density is further reduced relative to the contribution from salinity (not shown). This finding is consistent with our suggestion that the variations in temperature can be explained primarily by variations in vertical mixing.

We would expect the changes in vertical mixing to affect the salinity profiles as well as the temperature profiles. In particular, in view of the mean structure shown in Fig. 11c, we would expect increases in vertical mixing 

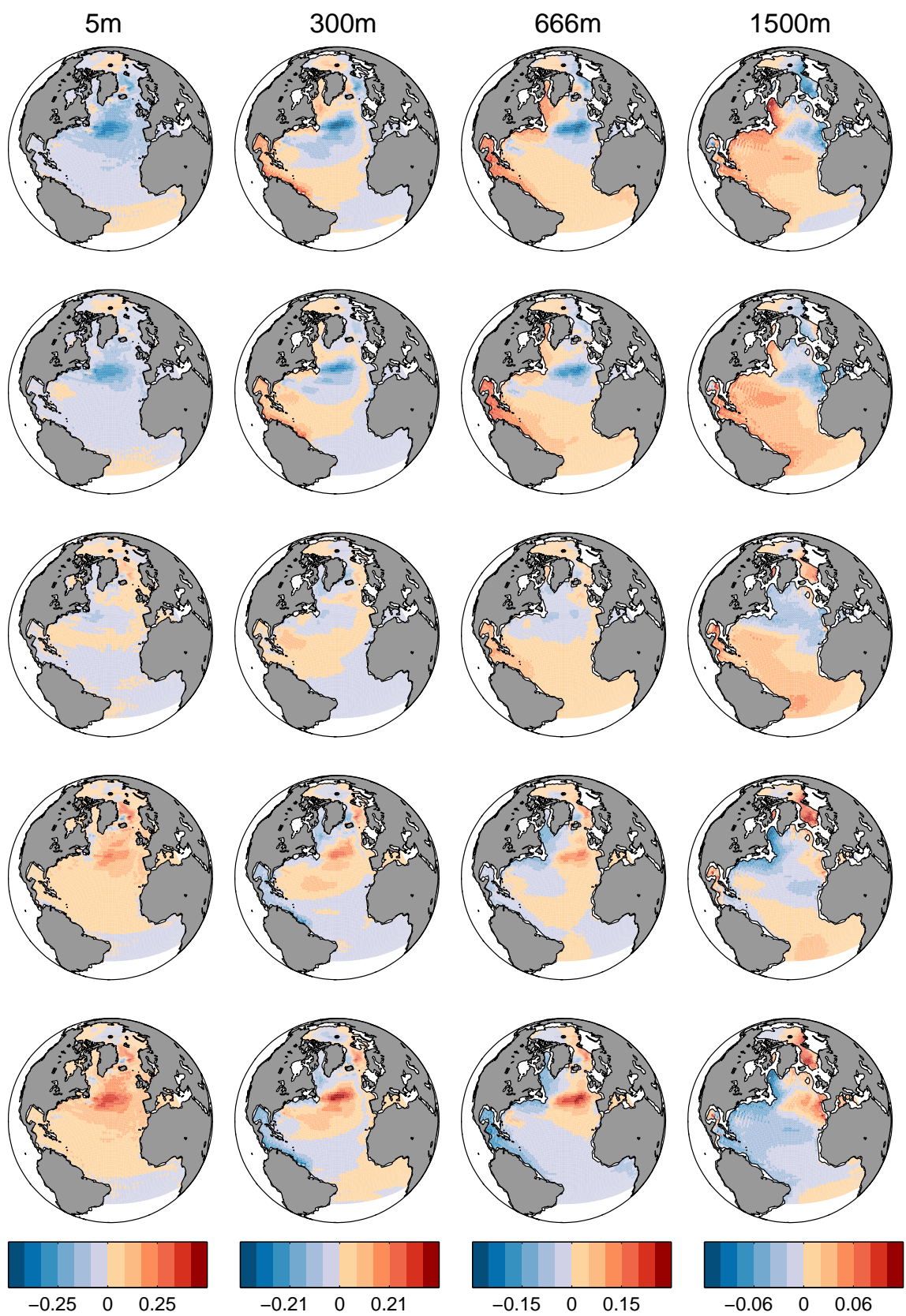

Figure 7: Evolution of temperature anomalies in the PC1-PC2 sub-space for depths $5 \mathrm{~m}, 300 \mathrm{~m}, 666 \mathrm{~m}$ and $1500 \mathrm{~m}$ as described in the text. The phases shown are $\psi=\left[\frac{3 \pi}{4}, \pi, \frac{5 \pi}{4}, \frac{3 \pi}{2}, \frac{7 \pi}{4}\right]$. The units are K per unit change in PC1. The model bathymetry is shown with a thin black contour.

to raise near surface salinity and to decrease salinity below $\sim 300 \mathrm{~m}$. Fig. 11d shows that, as the cycle evolves from MOC minimum to MOC maximum, increases in near surface salinity are seen initially, but subsurface decreases are not (except a very small decrease from $\psi=\frac{3 \pi}{4}$ to $\psi=\pi$ ). This finding suggests that changes in convection are not the only important process affecting salinity in this region. Closer inspection of Fig. 11d shows that below a few hundred metres salinity generally increases from MOC minimum to MOC maximum. The most likely explanation for these increases is that they reflect increased transport of Atlantic water into the Nordic Seas, in response to the progressive acceleration of the MOC. Although this transport is concentrated at the eastern side of the basin, part of the Atlantic water subsequently spreads westward through advection and lateral mixing.

An exception to the general pattern of subsurface salinity increases is found in the initial stage following a MOC minimum (between $\psi=\frac{3 \pi}{4}$ and $\psi=\pi$ ). During this interval there is a small decrease in salinity below about $500 \mathrm{~m}$, 

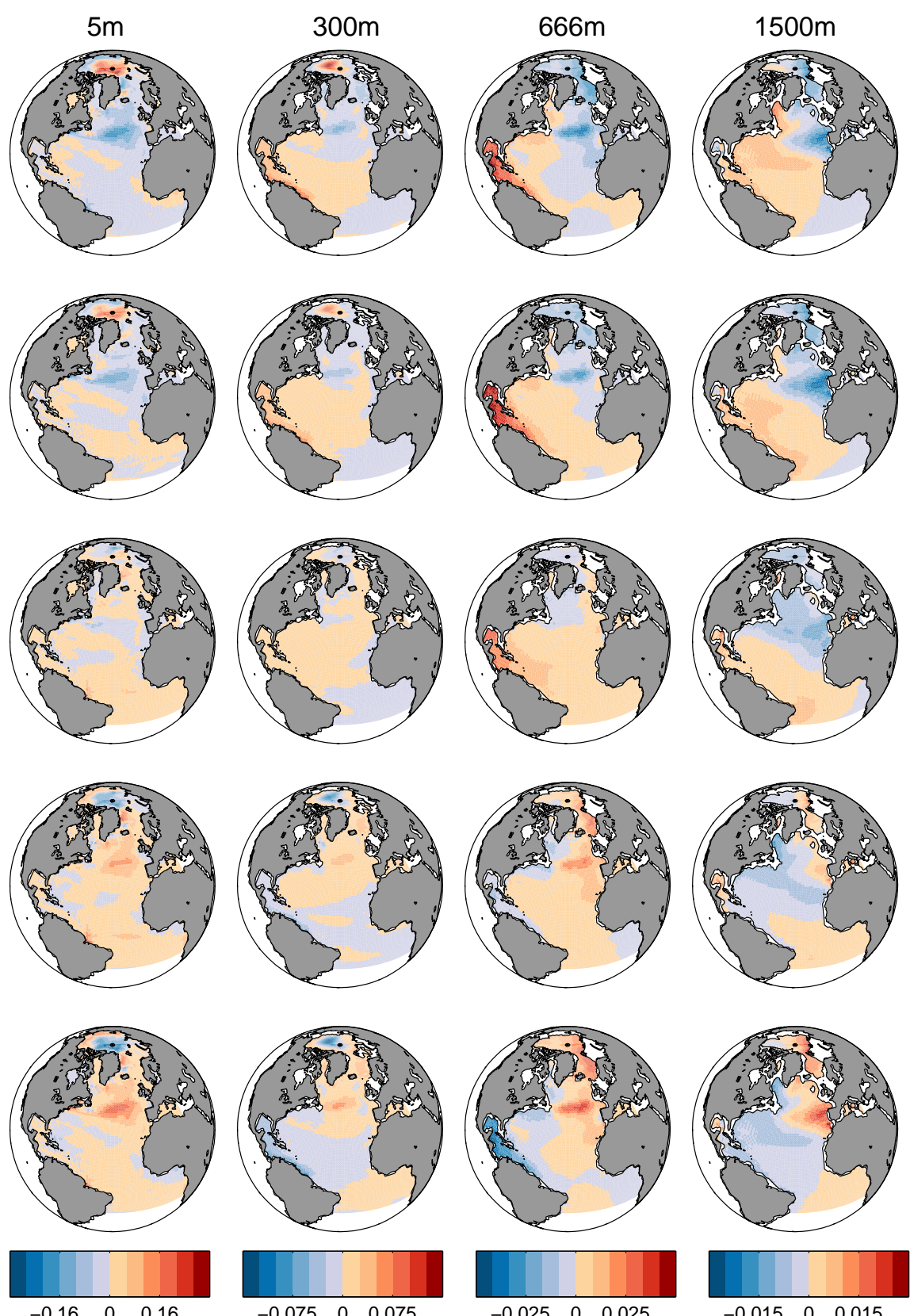

Figure 8: Evolution of salinity anomalies in the PC1-PC2 sub-space for depths $5 \mathrm{~m}, 300 \mathrm{~m}, 666 \mathrm{~m}$ and $1500 \mathrm{~m}$ as described in the text. The phases shown are $\psi=\left[\frac{3 \pi}{4}, \pi, \frac{5 \pi}{4}, \frac{3 \pi}{2}, \frac{7 \pi}{4}\right]$. The units are psu per unit change in PC1. The model bathymetry is shown with a thin black contour.

but there are large increases near the surface. What is the source of this additional salinity at the surface? The fact that the increases are found in the near-surface waters, suggests that the origin is likely to be the outflow of Arctic water in the East Greenland Current. Fig. 8 (top row) shows that at an MOC minimum near surface salinity in the Arctic is at a maximum. If the anomalous transport of salinity out of the Arctic were (roughly) proportional to the salinity gradient between the Arctic and the Nordic Seas, we would anticipate enhanced southward transport of salinity into the Nordic Seas at this stage. A rigorous proof of the mechanism we propose would require a complete budget analysis for salinity, temperature and density in the Nordic Seas. Unfortunately we lack the necessary diagnostics to perform such calculations. However, we have been able to examine the salinity tendency due to advection. We found that 20 years before a maximum in the MOI the advective tendency shows positive values stretching along the northeast coast of Greenland, with negative values in the Arctic north of Fram Strait (not 

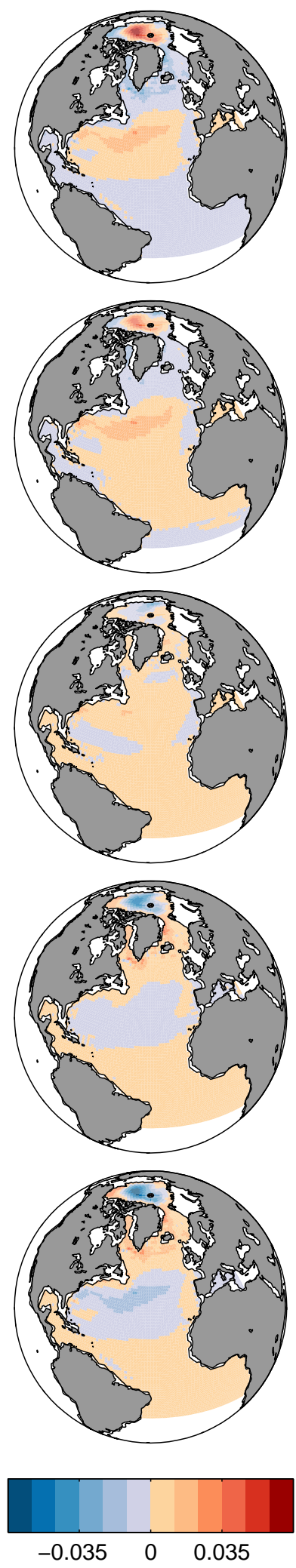

Figure 9: Evolution of density anomalies vertically integrated to $800 \mathrm{~m}$ in the $\mathrm{PC} 1-\mathrm{PC} 2$ sub-space as described in the text. The phases shown are $\psi=\left[\frac{3 \pi}{4}, \pi, \frac{5 \pi}{4}, \frac{3 \pi}{2}, \frac{7 \pi}{4}\right]$. Units are $\mathrm{kg} \mathrm{m}^{-2}$ per unit change in PC1. The model bathymetry is shown with a thin black contour.

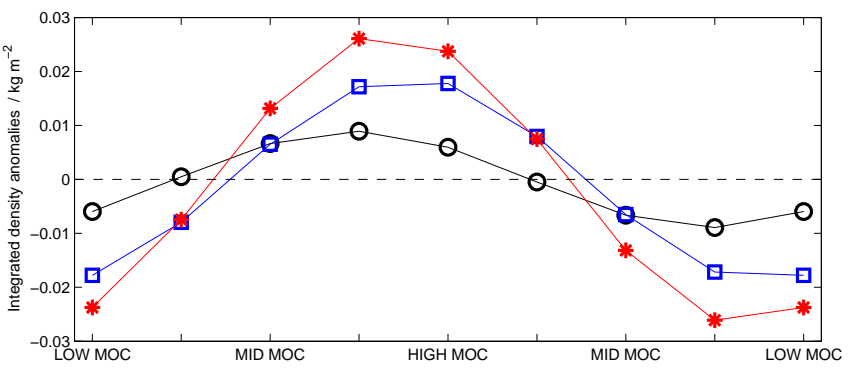

Figure 10: Contributions to density anomalies, vertically integrated to $800 \mathrm{~m}$, at $72^{\circ} \mathrm{N}$, averaged over $10-20^{\circ} \mathrm{W}$ for temperature (black circles) and salinity (blue squares). The total density anomaly for the same region is also shown (red stars). Note that the labels related to the 'MOC' are derived from the simplified circular trajectory in the sub-space of the leading PCs.

shown). This pattern supports our hypothesis of anomalous salinity advection out of the Arctic.

\subsubsection{Summary of mechanism}

We can now summarise our understanding of the processes that govern the density variations in the western Nordic Seas, beginning at an MOC minimum (these are also summarised in a schematic diagram in Fig. 12):

1. At the MOC minimum, enhanced transport of salinity out of the Arctic in the East Greenland Current causes surface salinity to rise. The increase in surface salinity promotes enhanced convection, causing surface temperature to rise and subsurface temperature to fall. The vertically integrated density (down to $800 \mathrm{~m}$ ) increases (primarily due to the increase of salinity, with additional contribution from the decrease in subsurface temperature), which causes the MOC to increase.

2. The increase of the MOC causes increased transport of Atlantic water into the Nordic Seas. This increased transport causes salinity to rise, further increasing the vertically integrated density, and acting as a positive feedback on the MOC.

3. Phase reversal. The increase in the MOC is associated with a decay of the major near surface salinity anomaly in the Arctic, and thus we expect a decrease in the anomalous transport of salinity in the East Greenland Current. This decrease causes freshening of the near surface waters in the western Nordic Seas (as can be seen in Fig. 11d for phases between $\psi=\frac{5 \pi}{4}$ and $\psi=\frac{7 \pi}{4}$ ), which progressively weakens convection. The weakening of convection causes sea surface temperature to fall and subsurface temperature to rise (Fig. 11c at $\psi=\frac{7 \pi}{4}$ ). The vertically integrated density decreases (primarily due to the 

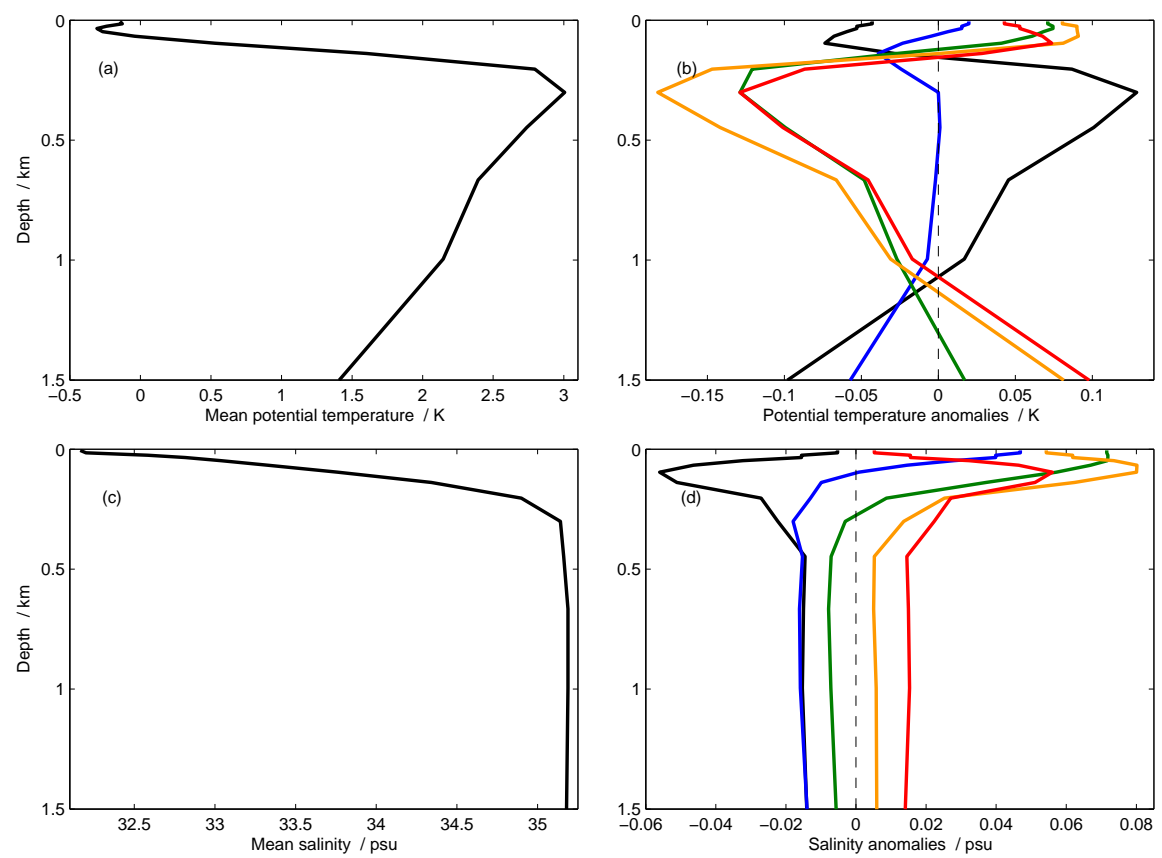

Figure 11: Profiles averaged over $10-20^{\circ} \mathrm{W}$ at $72^{\circ} \mathrm{N}$ of (a) mean temperature, (b) temperature anomalies at five phases of MOC, (c) mean salinity, (d) salinity anomalies at five phases of MOC. The phases shown in (b) and (d) are $\psi=\frac{3 \pi}{4}$ (black, low MOC), $\pi$ (blue), $\frac{5 \pi}{4}$ (green), $\frac{3 \pi}{2}$ (orange), $\frac{7 \pi}{4}$ (red, high MOC). Note that the references to the 'MOC' are derived from the simplified circular trajectory in the sub-space of the leading PCs.

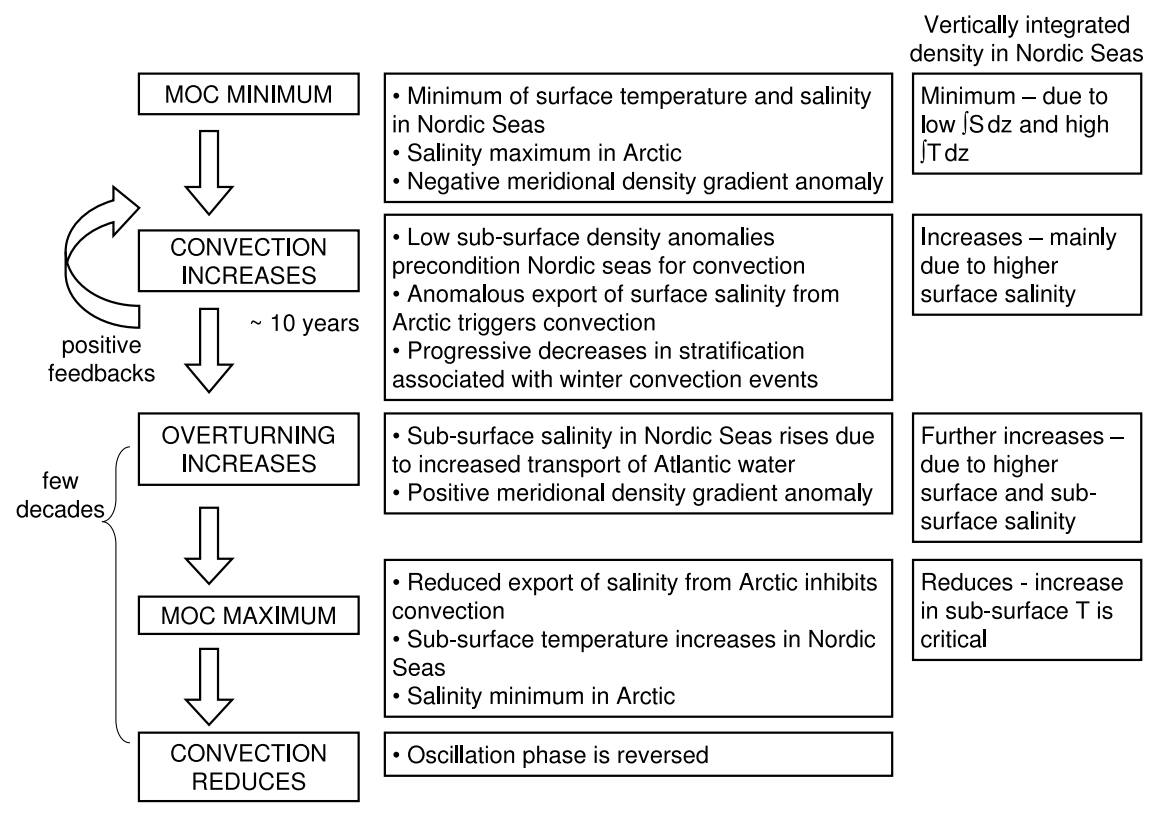

Figure 12: Summary schematic describing the processes responsible for the multi-decadal oscillation of the overturning in HadCM3. The local positive feedbacks that enhance convection are summarised in Fig. 15. 
increase of subsurface temperature) and the MOC follows.

In the above account the transport of salinity from the Atlantic into the Nordic Seas provides a positive feedback on the MOC, while the storage and release of salinity anomalies in the Arctic provides a delayed negative feedback, and probably sets the dominant timescale. This proposed mechanism differs from that suggested by Vellinga and $\mathrm{Wu}(2004)$, in which the transport to high latitudes of salinity anomalies generated in the tropical Atlantic provided the delayed negative feedback and there was no role for the Arctic. We have not attempted in this study to explain the processes that control the build up and release of near surface salinity anomalies in the Arctic, except to assume that the release is approximately proportional to the anomalous gradient of surface salinity between the Arctic and the Nordic Seas. We suspect that the build up of Arctic salinity anomalies is a lagged response to the changes in the MOC. The evidence from Fig. 8 of deep salinity anomalies propagating from the Nordic Seas into the Arctic provides some support for this suggestion (also see the animated anomalies in Fig. 16).

A similar low frequency ocean mode, also excited by the atmosphere, was found in the ECHAM5/MPI-OM model (Jungclaus et al. 2005). The mechanism identified also relies on changes in the storage and release of freshwater from the Arctic Ocean as the key feedback. There are strong similarities in the evolution of their mode with that described here (compare their Fig. 9 with our Figs. 7, 8). However, in HadCM3 the largest variability in convection is found in the Nordic Seas, whereas in their model the Labrador Sea is the main convection site and this requires differences in the mechanism. Delworth et al. (1997) also described how variations in salinity in the Arctic and Greenland Seas can affect the THC in a coupled model.

An important question is whether this type of variability is present in the real Arctic system. Polyakov et al. (2004) describe observed multi-decadal changes in properties of the inflow of Atlantic water into the Arctic and how these changes can further affect the outflows into the Nordic Seas in a similar way to that described here, though the observed time series last just one cycle and appears to be influenced by anthropogenic signals.

\subsection{Ocean-atmosphere interactions and im- pacts on climate}

The mechanism we have described is an internal mode of ocean variability. It is likely to be influenced by stochastic fluctuations arising in the atmosphere but does not rely on ocean-atmosphere interactions for its existence (i.e. it is not a coupled mode in the way that ENSO is). It does, however, have some weak impacts on climate. Fig. 13 shows lagged regressions of SST, MSLP, surface air temperature and precipitation onto the leading principal com- ponent, $\mathrm{PC} 1$, for the full 1100 years analysed. The particular lag shown is around 10 years before an MOC maximum and is chosen to show the largest signals. The units given are per unit change in PC1.

Just before an MOC maximum there is a general warming of the SSTs north of the equator, particularly in the NAC region $\left(\sim 0.3-0.5^{\circ} \mathrm{C}\right)$ and in the Nordic seas $(\sim$ $0.3-0.4^{\circ} \mathrm{C}$ ), and a small cooling to the south of the equator. There is a small, but statistically significant, MSLP reduction $(\sim 0.3 \mathrm{mb})$ over the convection region in the Nordic seas, which would project onto the positive phase of the NAO. This is also associated with a $\sim 1^{\circ} \mathrm{C}$ warming of the air temperature and a $\sim 6 \%$ decrease in the ice fraction (not shown) in the same region. There is also a general warming of northern hemisphere air temperature of $\sim 0.1^{\circ} \mathrm{C}$, which is enhanced to $\sim 0.4^{\circ} \mathrm{C}$ over the NAC. The position of the Atlantic ITCZ varies roughly in phase with the MOC, with a northward movement associated with a high MOC. There is also increased precipitation over the warm convection region in the Nordic seas. The precipitation anomalies in the tropics and in the Nordic seas are a few percent of the local mean values, consistent with the general picture of weak impacts on climate.

The climate impacts illustrated in Fig. 13 are similar to those identified in HadCM3 by Vellinga and $\mathrm{Wu}$ (2004) (their Fig. 6) and Knight et al. (2005, 2006). However, these authors did not highlight the fact that SST and variations in the Nordic Seas lead the MOC. This fact is illustrated by the solid lines in Fig. 14, which shows the cross-correlation between an index of Nordic Seas SST (averaged over the region $65^{\circ} \mathrm{N}-80^{\circ} \mathrm{N}$ and $25^{\circ} \mathrm{W}-0^{\circ} \mathrm{W}$ ) and the MOI for different time periods. For the two periods of coherent oscillations the maximum correlation is found when the SST index leads the MOI by 5-8 years. In the intervening period the cross-correlation shows a similar asymmetry but is flat between about $0-5$ years. The peak correlations are notably higher $(0.88$ and 0.62 , as compared to 0.44) for the two periods of coherent oscillation. The surface salinity in the same region leads the MOC by 10-20 years during the coherent oscillating periods (dashed lines in Fig. 14), consistent with the idea that the anomalous salinity transport from the Arctic is the trigger for convection.

The idea that climate impacts at high latitudes lead rather than lag the MOC is at odds with the traditional idea that increased poleward heat transport by the ocean will cause an accumulation of heat at high latitudes and, perhaps after some delay, an enhanced heat flux into the atmosphere. However, the explanation of Fig. 14 follows directly from the mechanism outlined in Section 4.2.3. Because of the subsurface temperature maximum, high SST in the Nordic Seas is a signature of convection. Furthermore, SST varies in phase with the vertically integrated density. It follows that SST provides a proxy for the variations in density that drive the MOC.

Associated with the SST anomalies in the Nordic Seas 

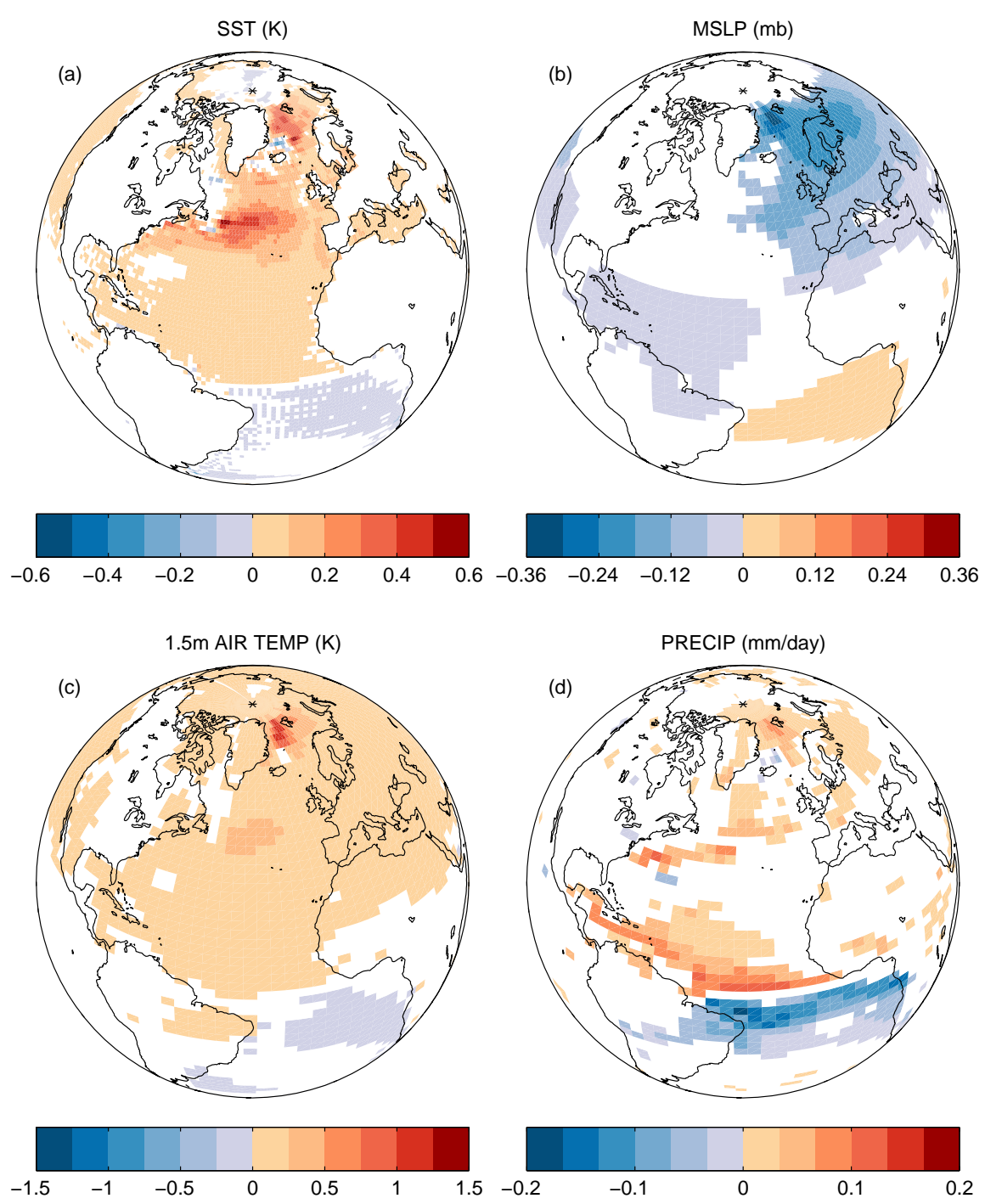

Figure 13: Surface climatic impacts of changes in the strength of the MOC. Lagged regressions of various fields onto PC1, leading an MOC maximum by around 10 years. The units shown are per unit change of PC1. (a) SST. (b) Mean sea level pressure. (c) Surface air temperature. (d) Precipitation rate - note red colours are increased precipitation. White areas are not significant at $5 \%$ level.

are anomalies in the ocean-atmosphere heat flux, with high SST associated with enhanced cooling of the ocean (not shown). The associated warming of the atmosphere is likely to be the cause of the negative SLP anomaly seen in Fig. 13b (see Gamiz-Fortis and Sutton (2007) for further evidence and discussion). These air-sea interactions have the potential to amplify convection through positive feedbacks, as illustrated in Fig. 15. Convection leads to elevated SST, thus increasing the cooling of ocean surface and promoting further convection. This feedback could be enhanced by two further effects of raised SST: 1) melting of sea-ice, which exposes more ocean surface and thereby further enhances cooling; 2) the atmospheric response of negative SLP, which will cause surface Ekman divergence and therefore upwelling in the ocean, which will in turn act to reduce stratification and further promote convec- tion. These postulated positive feedbacks are fast processes, and are therefore unlikely to be involved in setting the timescale of the MOC variability in HadCM3; however, they could play a role in setting the amplitude.

Detailed comparison with observations is beyond the scope of this study, but it is interesting to note that the pattern of high latitude warming seen in Fig. 13c shows considerable similarity to the pattern of observed warming between 1920 and 1940 that was described by Johannessen et al. (2004) (see their Figures $2 \mathrm{a}$ and 2b). The similarity supports the hypothesis that this warming was a feature of natural climate variability related to the Atlantic MOC (also see Delworth and Knutson 2000). (Bengtsson et al. (2004) describe an alternative hypothesis in which the focus is on regional air-sea interactions rather than basin-scale MOC change.) Knight et al. (2005, 2006) de- 


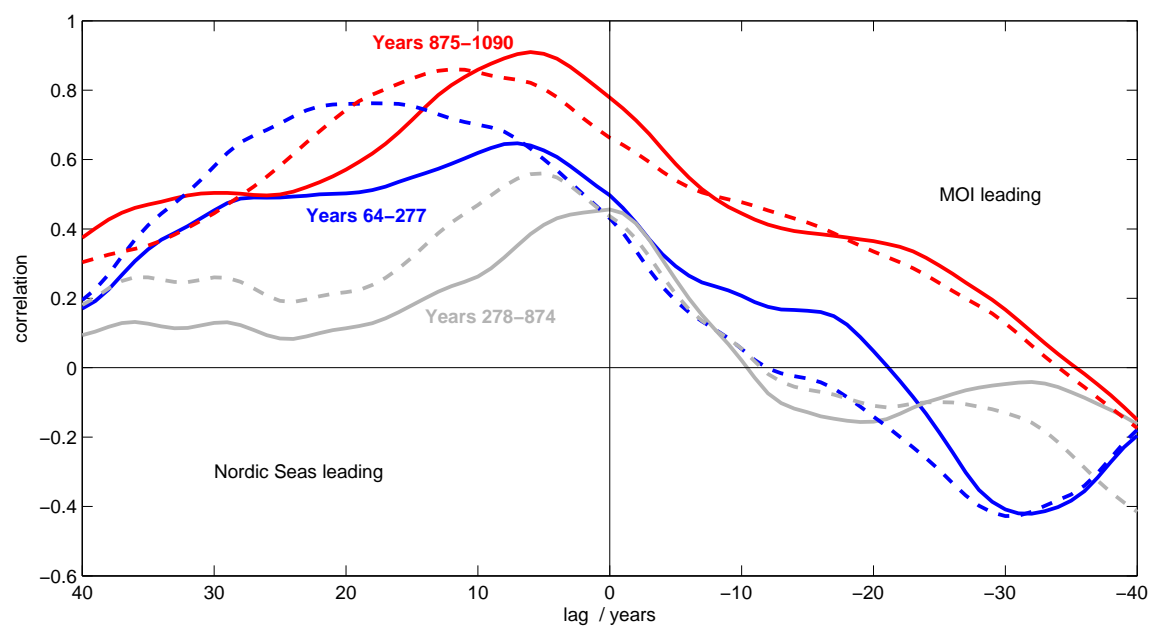

Figure 14: Lagged cross-correlations between the MOI and Nordic Seas SST (solid lines) and SSS (dashed lines) for three different time slices of the analysis as labelled. The indices have been decadally filtered.

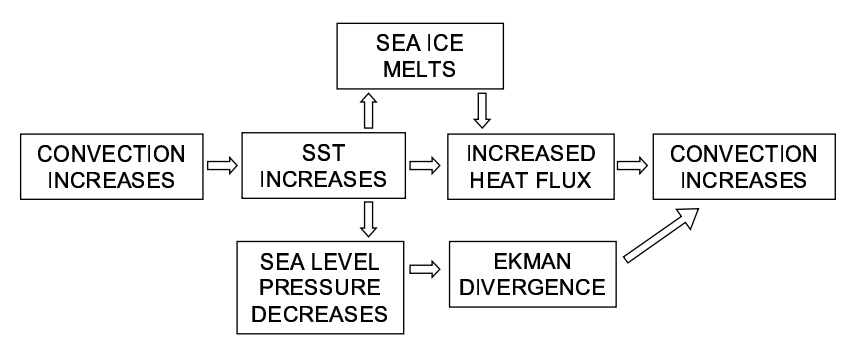

Figure 15: Summary schematic showing the rapid positive feedbacks which help enhance convection in the Nordic Seas.

scribe evidence that multi-decadal variability of the Atlantic MOC may have been an important driver of other observed climate signals, including variability in the Atlantic ITCZ as suggested by Fig. 13d.

\section{Conclusions and discussion}

It has been demonstrated that bivariate three-dimensional EOFs of temperature and salinity provide a data adaptive method to efficiently describe variability of the Atlantic THC. Our key findings using HadCM3 can be summarised as follows:

- The two leading modes explain nearly $60 \%$ of the decadal variance of the MOI at zero lag. Allowing for lags the leading mode alone can explain $54 \%$ of the decadal variance or $74 \%$ of the multi-decadal variance of the MOI.

- A trajectory plotted in the sub-space of the leading EOFs showed evidence of coherent oscillations. Such episodes are of great interest for predictability. There are therefore possible applications in terms of a future forecasting system for the THC, and potentially, socio-economic benefits through predicting the climate impacts. This analysis also suggested that there are may be different regimes of natural variability of the THC in HadCM3, possibly due to the presence of a bifurcation.

- The mechanism identified to explain this multi-decadal variability (see schematics in Fig. 12 and Fig. 15) is a purely ocean mode, controlled by changes in convection in the Nordic seas. The essence of the proposed oscillation is:

- convection in the Nordic Seas, likely triggered by anomalous salinity export from the Arctic, creates high density anomalies which influence the MOC,

- rapid positive feedbacks on convection associated with the effects of convection on SST, sea ice and air-sea fluxes help maintain convection,

○ the meridional density gradient rises, along with the MOC. The acceleration of the MOC is associated with increased transport of saline Atlantic water into the convection region, acting initially as a positive feedback,

o the convection is capped by anomalous fresh water, likely exported from the Arctic, and the phase is reversed.

This mechanism is different to that described by Vellinga and $\mathrm{Wu}$ (2004) who argued that a shift in the position of the Atlantic ITCZ provided the necessary negative feedback on the low frequency MOC variations in HadCM3.

- The surface climate effects of this mechanism include changes in SST, ice extent and air temperature, especially in the Nordic seas, a shift in the position 
of the ITCZ, as well as a weak feedback onto the NAO. Surprisingly, we have found that the surface climate signals often lead changes in the overturning strength.

- There are qualitative similarities between these modelled climate signatures and observations of multidecadal variability in the atmosphere and ocean. Detailed, more quantitative, comparisons are deferred to a future study.

We finally note that this study has used a global climate model of moderate resolution and there are certainly important processes which HadCM3 does not resolve adequately. Applying the techniques developed here on higher resolution models will be valuable to explore the robustness of the results. The identified potential predictability of this mode will be explored in a further paper.

\section{Acknowledgements}

We thank Simon Tett for providing the HadCM3 control run data and the two reviewers for their suggestions to improve the paper. EH is funded by the UK Natural Environment Research Council under the thematic Rapid Climate Change programme (RAPID). RS is supported by a Royal Society University Research Fellowship.

Fig. 16: An animated version of Figs. 7, 8 is available with the online version and on the author's website.

\section{References}

Bengtsson L, Semenov VA, Johannessen OM (2004) The early twentiethcentury warming in the Arctic - a possible mechanism. J Climate 17: $4045-4056$

Collins M, Sinha B (2003) Predictability of decadal variations in the thermohaline circulation and climate. Geophys Res Lett 30 doi: 10.1029/2002GL016504

Delworth TL, Greatbatch RJ (2000) Multi-decadal thermohaline circulation variability driven by atmospheric surface flux forcing. J Climate 13: $1481-1495$

Delworth TL, Knutson TR (2000) Simulation of Early 20th Century Warming. Science 287: $2246-2250$

Delworth TL, Manabe S, Stouffer RJ (1997) Multidecadal climate variability in the Greenland Sea and surrounding regions: a coupled model simulation. Geophys Res Lett 24: $257-260$

Delworth TL, Mann ME (2000) Observed and simulated multi-decadal variability in the Northern Hemisphere. Climate Dyn 16: $661-676$ doi: $10.1007 / \mathrm{s} 003820000075$

Dong B, Sutton RT (2005) Mechanism of interdecadal thermohaline circulation variability in a coupled ocean-atmosphere GCM. J Climate 18: $1117-1135$

Flament P (2002) A state variable for characterizing water masses and their diffusive stability: spiciness. Prog Ocean 54: 493-501

Gamiz-Fortis S, Sutton RT (2007) Quasi-periodic fluctuations in the Greenland-Iceland-Norwegian Seas region in a coupled climate model. Climate Dyn submitted
Gavart M, De Mey P (1997) Isopycnal EOFs in the Azores Current region: A statistical tool for dynamical analysis and data assimilation. J Phys Ocean 27: $2146-2157$

Gordon C, Cooper C, Senior CA, Banks H, Gregory JM, Johns TC, Mitchell JFB, Wood RA (2000) The simulation of SST, sea ice extents and ocean heat transports in a version of the Hadley Centre coupled model without flux adjustments. Climate Dyn 16: $147-168$

Johannessen OM, Bengtsson L, Miles MW, Kuzmina SI, Semenov VA, Alekseev GV, Nagurnyi AP, Zakharov VF, Bobylev LP, Pettersson LH, Hasselmann K, Cattle HP (2004) Arctic climate change: observed and modelled temperature and sea-ice variability. Tellus A 56: 328 341 doi:10.1111/j.1600-0870.2004.00060.x

Johnson HL, Marshall DP (2002) A theory for the surface Atlantic response to thermohaline variability. J Phys Ocean 32: 1121-1132

Jungclaus JH, Haak H, Latif M, Mikolajewicz U (2005) Arctic-North Atlantic interactions and multi-decadal variability of the meridional overturning circulation. J Climate 18: 4013 - 4031

Kleeman R, Tang Y, Moore AM (2003) The calculation of climatically relevant singular vectors in the presence of weather Noise as applied to the ENSO problem. J Atmos Sci 60: 2856 - 2868

Knight JR, Allan RJ, Folland CK, Vellinga M, Mann ME (2005) A signature of persistant natural thermohaline circulation cycles in observed climate. Geophys Res Lett 32 doi:10.1029/2005GL024233

Knight JR, Folland CK, Scaife AA (2006) Climate impacts of the Atlantic Multidecadal Oscillation. Geophys Res Lett 33 doi: 10.1029/2006GL026242

Levitus S, and coauthors World Ocean Atlas 2005. U.S. Government Printing Office, Washington D.C. 2006

Ottera OH, Drange H, Bentsen M, Kvamsto NG, Jiang D (2004) Transient response of the Atlantic Meridional Overturning Circulation to enhanced freshwater input to the Nordic Seas-Arctic Ocean in the Bergen Climate Model. Tellus A 56: 342-361 doi:10.1111/j.16000870.2004.00063.x

Pardaens AK, Banks HT, Gregory JM, Rowntree PR (2003) Freshwater transports in HadCM3. Climate Dyn 21: 177 - 195 doi: $10.1007 / \mathrm{s} 0038200303246$

Polyakov IV, Alexeev V, Belchansky GI, Dmitrenko IA, Ivanov V, Kirillov S, Korablev A, Steele M, Timokhov LA, Yashayaev I (2007) Arctic Ocean freshwater changes over the past 100 years and their causes. J Climate submitted

Polyakov IV, Beszczynska A, Carmack EC, and coauthors (2005) One more step toward a warmer Arctic. Geophys Res Lett 32 doi: 10.1029/2005GL023740

Polyakov IV, Bhatt US, Colony RL, Simmons HL, Walsh JE, Alekseev GV, Timokhov LA, Zakharov VF, Walsh D (2004) Variability of the Intermediate Atlantic Water of the Arctic Ocean over the Last 100 Years. J Climate 17: $4485-4497$

Preisendorfer RW Principal Component Analysis in Meteorology and Oceanography. Elsevier. 1988

Thorpe RB, Gregory JM, Johns TC, Wood RA, Mitchell JFB (2001) Mechanisms determining the Atlantic thermohaline circulation response to greenouse gas forcing in a non-flux-adjusted coupled climate model. J Climate 14: $3102-3116$

Vellinga M, Wu P (2004) Low-latitude freshwater influence on centennial variability of the Atlantic thermohaline circulation. J Climate 17: $4498-4511$

Wu P, Wood R, Stott P (2004) Does the recent freshening trend in the North Atlantic indicate a weakening thermohaline circulation? Geophys Res Lett 31 doi:10.1029/2003GRL018584 